Article

\title{
Assessment Impacts of Weather and Land Use/Land Cover (LULC) Change on Urban Vegetation Net Primary Productivity (NPP): A Case Study in Guangzhou, China
}

Yingchun Fu ${ }^{1}$, Xueyu Lu ${ }^{1}$, Yaolong Zhao ${ }^{1, *}$, Xiantie Zeng ${ }^{1,2}$ and Lili Xia ${ }^{1}$

1. School of Geography, South China Normal University, Guangzhou 510631, China;

E-Mails: fuyc@scnu.edu.cn (Y.F.); praymer1007@gmail.com (X.L.); feandyi@163.com (X.Z.); hslily@163.com (L.X.)

2. China RS Geoinformatics Co. Ltd., Dongguan 523808, China

* Author to whom correspondence should be addressed; E-Mail: yaolong@scnu.edu.cn;

Tel.: +86-189-2610-3348; Fax: +86-20-8521-5910.

Received: 22 June 2013; in revised form: 13 August 2013 / Accepted: 13 August 2013 /

Published: 20 August 2013

\begin{abstract}
Net primary productivity (NPP) can indicate vegetation ecosystem services ability and reflect variation response to climate change and human activities. This study applied MODIS-1 km NPP products to investigate the NPP variation from 2001 to 2006, a fast urban expansion and adjustment period in Guangzhou, China, and quantify the impacts of weather and land use/land cover (LULC) changes, respectively. The results showed that the NPP mean value increased at a rate of $11.6 \mathrm{~g} \cdot \mathrm{C} \cdot \mathrm{m}^{-2} \cdot \mathrm{yr}^{-1}$ during the initial three years and decreased at an accelerated rate of $31.0 \mathrm{~g} \cdot \mathrm{C} \cdot \mathrm{m}^{-2} \cdot \mathrm{yr}^{-1}$ during the final three years, resulting in a total NPP loss of approximately $167 \times 10^{6} \mathrm{~g} \cdot \mathrm{C}$. The spatiotemporal of NPP varied obviously in the central area, suburb and exurb of Guangzhou driven by three patterns of weather and LULC changes. By the interactive effects and the weather variation dominated effects, NPP of most areas changed slightly with dynamic index less than $5 \%$ of NPP mean value in the central area and the suburb. The LULC change dominated effects caused obvious NPP reduction, by more than $15 \%$ of the NPP mean value, which occurred in some areas of the suburb and extended to the exurb with the outward urban sprawl. Importantly, conversion from wood grassland, shrublands and even forests to croplands occupied by urban landscapes proved to be a main process in the conversion from high-NPP coverage to low-NPP coverage, thereby leading to the rapid degradation of urban carbon stock capacity in urban fringe areas. It is helpful for government to monitor urban ecological health and safety and make relevant policies.
\end{abstract}


Keywords: NPP; spatiotemporal pattern; weather variation; LULC change; effects

\section{Introduction}

Until recent years, there has been growing evidence that activities to mitigate climate variation can have beneficial impacts on public health, with the need to avoid adverse environmental, social and economic consequences [1-6]. As the major source of greenhouse gas (GHG) emission, cities have been under tremendous pressure for energy conservation and emission reduction for decades [6-8], and have a limited capacity to reduce GHG due to consistently fast urbanization [9]. Improving dioxide carbon sequestration and storage by urban ecosystem is another effective way that will have benefits for social and economic aspects [10,11]. The global forest observation initiative (GFOI) is devoted to assessing the ability of global forest carbon tracking under the guide of Intergovernmental Panel on Climate Change (IPCC) [12].

Net primary productivity (NPP) is the rate of atmospheric carbon uptake by vegetation [13]. The NPP value equals the difference between the carbon absorbed by photosynthesis and the carbon released by autotrophic respiration [14,15]. The balance between the uptake and release of carbon plays a vital role in global biogeochemical carbon. NPP reflects not only the carbon sequestration ability of a plant community in its natural environment but also the vegetation's response to changes in climate and LULC [16-19]. Climate changes of long time or inter-annual weather variations can influence vegetation photosynthesis, respiration and decomposition of soil organic carbon (SOC) and have important effects on ecosystem productivity [20-22]. LULC change can directly alter the ecological system type, structure and function, thus leading to change in the ecological system's NPP and corresponding soil physical and chemical properties [22-25]. LULC change can make the ecological system vulnerable [26], increase GHG emissions [27] and decrease carbon storage, especially in coastal urban areas where there is rapid development. Therefore, in the context of global change, climate and LULC changes have an important and discernible influence on the NPP of natural and artificial ecological systems [28].

On the background of rapid global change, previous researches have investigated the impacts of environmental and urban factors on NPP, including the correlation between NPP and climate, humidity indices [29-31], population density, and gross domestic product (GDP) [32,33]. The light use efficiency (LUE) method, such as CASA (Carnegie Ames Stanford Approach) model, is often used to estimate NPP and indirectly indicate the influence of temperature, rainfall, LULC change and other parameters on NPP. However, highly heterogeneous, mosaic and complex urban ecological systems make it difficult to acquire bio-geographical parameters. Therefore, these studies generally focused on ecological systems with little LULC variation on the regional scale, such as the farming-pastoral region of northern China, the Taihu basin, the Ordos desert, farmland and forest surrounding urban areas, etc. [15,22,34-38]. While these studies are informative about the NPP variation, they lack information regarding the spatiotemporal patterns and evolution process.

Guangzhou was one of the earliest cities to conduct reforms and open up its policies in China in the 1970s. Since 2001, Greater Guangzhou has implemented an urban development and adjustment 
strategy of "eastern advance, western union, southern expansion, northern optimisation, and central region adjustment" in the 11th five-year plan. Rapid urbanisation has led to multiple ecological problems $[39,40]$, and differences in NPP between pre-and post-urban development are increasingly obvious in China [29,33]. Accordingly, the study of NPP dynamic variation and its driving mechanisms in Guangzhou can be regarded as a representative case in southern China. Hu et al. [29] noted that weather variations and human activities have led to a significant change in vegetation productivity in Guangzhou in a short period, from 2000 to 2008, and the responses by various types of vegetation cover were distinct in urban, rural, fringe. It is necessary for further research to investigate the effects pattern of weather variations and human activities on NPP in the developing greater Guangzhou. Moreover, the response of subtropical vegetation in low latitudes to the LULC changes are not well understood, and the results would fill knowledge gaps, especially in urban areas. Therefore, this paper attempts to achieve the following aims: (1) Estimating effects of weather and LULC changes in the perspective of urban expansion; and (2) Analyzing NPP spatiotemporal dynamic under different driving patterns in central areas, suburbs and exurbs in the urbanisation process. The results will provide support and a scientific basis for rational decision-making regarding land use and ecological environmental protection in Guangzhou.

\section{Study Area and Data Source}

\subsection{Study Area}

Greater Guangzhou $\left(22^{\circ} 26^{\prime}-23^{\circ} 56^{\prime} \mathrm{N}, 112^{\circ} 57^{\prime}-114^{\circ} 03^{\prime} \mathrm{E}\right)$ is located on the northern edge of the Pearl River Delta in southern China [41] (Figure 1). Stretching across the Tropic of Cancer, Guangzhou belongs to a subtropical, marine monsoon climate with an annual average temperature of 21.4-21.9 ${ }^{\circ} \mathrm{C}$. The annual precipitation is $1,612-1,909 \mathrm{~mm}$, and concentrates between April and September [42]. These characteristics — warm and rainy with adequate light and heat — are beneficial to plant growth. Guangzhou's population size has developed rapidly in recent years, and by the end of 2009, Guangzhou's population size was more than 10 million with a rapid growth rate of $1.54 \%$ from 1990-2009. The economy of Guangzhou has also increased rapidly, with the regional GDP (current prices) growing from $\$ 31.96$ billion in 1990 to $\$ 913.821$ billion in 2009 [41]. According to Guangzhou's overall planning (2010-2020) and Five-Year Plan (2011-2015), the city will be divided into three parts: the central area, the suburb and the exurb. The central area includes Liwan, Yuexiu, Haizhu, Tianhe, and Baiyun (south of Liuxihe and north second ring); the suburb includes Panyu, Luogang, Huadu, and Baiyun (outside of central area); and the exurb includes Conghua, Zengcheng, and Nansha.

\subsection{Data and Processing}

\subsubsection{MOD17A3 NPP Product and Uncertainty}

This study applies MOD17A3 annual NPP product with a spatial resolution of $1 \mathrm{~km}$ of Guangzhou as the study input data from 2001 to 2006 . These data are freely available to the public from the Numerical Terra dynamic Simulation Group (NTSG) [43]. These products are saved as formatted HDF 
EOS files in a two-dimensional array with 1,200 columns and 1,200 rows in a Sinusoidal projection [44]. A specific MODIS tool of ENVI software, MODIS Reprojection Tool (MRT), was used to transform the tiles into the Albers Conical Equal Area projection. Some pixels of the images with NPP values out of range of the triple standard deviation and the ineffective values were omitted.

Figure 1. Location of the study area.

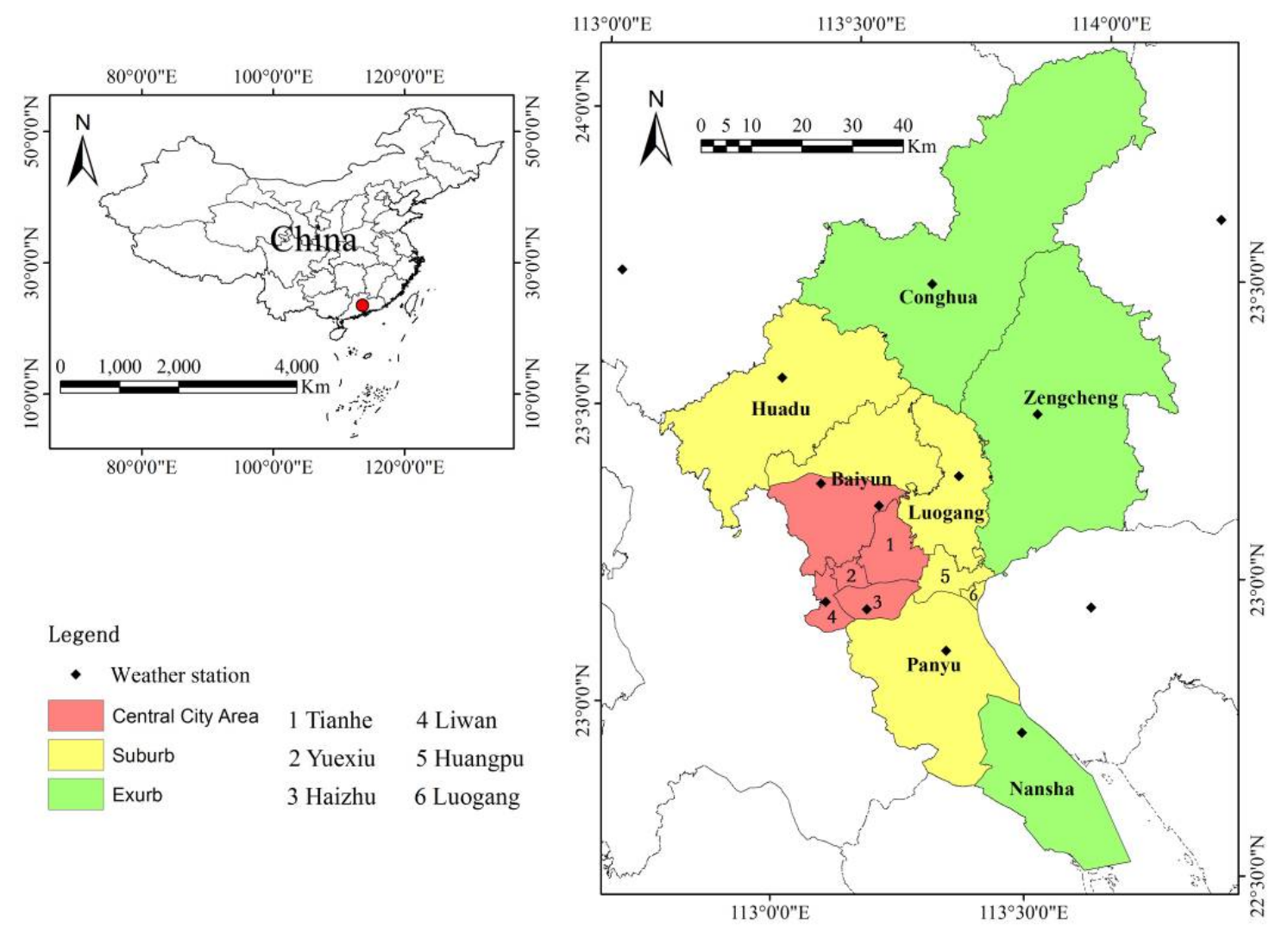

The three sources of MOD17 inputs for each pixel included MODIS land cover products, FPAR and LAI products, and daily meteorological data, which are derived from MOD12Q1, MOD15A2, and Data Assimilation Office (DAO) data sets, respectively. MOD12Q1 accuracies are within the range of $70 \%-80 \%$ due to errors between similar classes. The MOD15A2 and DAO dataset in Collection 5 MOD17 also have an improved correlation ( $\sim 81 \%)$ compared with the observational data. Temporal filling and non-linear spatial interpolation approaches have considerably improved the quality of these datasets [45]. All three upstream inputs as well as the algorithm itself can introduce uncertainties in MOD17 data. In the following reports, validation based on field measurements has demonstrated uncertainties associated with the MOD17 products [46]. First, a comparison of MODIS annual GPP values with field data collected from 37 Ameriflux and Fluxnet sites distributed throughout North America, mid-latitude zones, polar regions and a wide variety of ecosystem types, including bracketing forests, shrublands and grasslands, resulted in an overall high consistency $\left(R^{2}=0.6993\right.$; relative error $=19 \%$ ) [47]. Moreover, the validation of NPP data using Ecosystem Model-Data Intercomparison (EMDI) data compiled from more than 1,000 ground points resulted in an overall high consistency $\left(R^{2}=0.77\right)$. Significantly, using scaled and aggregated BigFoot Project data measured at nine different ecosystem flux towers throughout the world, Turner et al. [48] found that the annual GPP and NPP 
showed a close agreement between the MODIS and the Bigfoot products. In addition, a local rice map used for rice yield estimation in southern China generated using MOD17 GPP/NPP products was shown to have a low relative error of approximately $10 \%$ based on validation with actual yields [29].

\subsubsection{Land Use/Land Cover from Landsat TM}

A series of Landsat Thematic Mapper (TM) multispectral images acquired on November 2001, January 2003 and November 2006 in Guangzhou served for the actual Land use/Land covers in Guangzhou. Landsat TM image had a spatial resolution of $30 \mathrm{~m}$ with seven bands from visible to thermal infrared. High resolution images were used to provide land cover details to reference samples of classification. There are a SPOT image with four multispectral bands of $10 \mathrm{~m}$ and a $2.5-\mathrm{m}$ panchromatic band acquired in December 2006, and digital orthorectified aerial photographs acquired in 2001 and 2003. TM and SPOT multispectral images were calibrated into the geographic reference system of WGS_1984 and initially calibrated to at-sensor radiance and atmospherically corrected to estimate the surface reflectance using a radiometric calibration technique based on the image header file, solar elevation angle, gain offset and calibration parameters of the image. Next, an atmospheric correction was performed on both images using one tool of ENVI software, Fast Line-of-sight Atmospheric Analysis of Spectral Hypercube (FLAASH) atmospheric correction method [49]. FLAASH is a method used to correct sensor radiance for atmospheric effects by mathematically modelling the physical behaviour of radiation as it passes through the atmosphere.

\subsubsection{Meteorological Data}

The climate dataset employed in this work to analyze the impacts on NPP variation, which covers the period of 2000-2007, includes monthly mean temperature, total monthly precipitation across greater Guangzhou. Specifically, some historical records of monthly temperature and precipitation were derived from 13 climatological stations from the online Guangzhou Statistical information [50] and relevant Statistical Yearbook. As an important interpolation method, kriging has been widely used for sampling at each pixel in terms of the climate factors from the site-based information.

\section{Methods}

\subsection{Land Use/Land Cover Classification}

Spectral angle mapper (SAM) classifier used for target discrimination compares the spectral angle between the reference spectrum vector and each target spectral vector in an n-Dimensional space [49,51]. When the spectral angle between the pixel and the reference object is less than the given threshold value, the pixel can be considered in the same class as the reference object. The SAM combined with different vegetation distribution rules can be adopted to improve the classification accuracy of six species of forest-woodland-savannah mosaic, and compared with the maximum likelihood classification (MLC); the classification accuracy was increased by $10 \%$ in comparison to $85.2 \%$ for MLC [52]. By removing spectrum noise or making differential spectrum, SAM can be adopted to eliminate the influence of the vegetation environmental background and the phenomenon caused by the same object with different spectrums to improve the vegetation identification precision. 
For multi-vegetation classifications in urban areas, the hierarchical classification binary tree accounted for the spectral separability was designed to provide the class set and classified sequence in each node, as well as the matching thresholds. The SAM running along hierarchical tree nodes can recognise optimised classification based on the spectral separability level; therefore, Spectral Angle Mapper decision tree method was used to map 11 covers using Landsat TM images in the mega-city of Guangzhou, China.

According to the actual land covers in Guangzhou, there are eight vegetation classes selected from the International Geosphere-Biosphere Program (IGBP) schemes in Table 1 [53]. In addition, the LULC types of "Urban and Built-up Lands", "Water Bodies" and "Barren" are also identified with high accuracy.

Table 1. International Geosphere-Biosphere Program (IGBP) criteria used for the land use/land cover classes.

\begin{tabular}{|c|c|c|}
\hline LULC Types & $\begin{array}{c}\text { Canopy } \\
\text { Cover }(\%)\end{array}$ & Canopy Woody Communities \\
\hline Evergreen Needleleaf Forests $(*$ ENF) & $>60$ & Green Needleleaf forests species. \\
\hline Evergreen Broadleaf Forests (* EBF) & $>60$ & Green Broadleaf forests species. \\
\hline Mixed Forests $(*$ MF) & $>60$ & Mosaic of multiple forest species, but no single canopy greater than $60 \%$. \\
\hline (Open) Shrublands (* SL) & $10-60$ & Woody vegetation less than 2 meters tall and mainly shrub. \\
\hline Woody Savannas (* WS) & $30-60$ & Herbaceous and other understory systems. \\
\hline Grasslands (* GL) & $10-60$ & Lands with herbaceous types of cover. Tree and shrub cover is less than $10 \%$. \\
\hline Croplands $(* \mathrm{CL})$ & $10-30$ & Temporary crops followed by harvest and bare soil. \\
\hline $\begin{array}{l}\text { Cropland/Natural Vegetation } \\
\text { Mosaics (* CL\&NVM) }\end{array}$ & $10-60$ & $\begin{array}{l}\text { A mosaic of croplands, forests, shrubland and grasslands in which no one } \\
\text { component comprises more than } 60 \% \text { of the landscape. }\end{array}$ \\
\hline Barren $(* \mathrm{BR})$ & $0-10$ & $\begin{array}{l}\text { Exposed soil, sand, rocks or snow that never has more than } 10 \% \\
\text { vegetated cover. }\end{array}$ \\
\hline Water bodies $(* \mathrm{WB})$ & NA & Oceans, seas, lakes, reservoirs and rivers. \\
\hline Urban and Built-up Lands (*U\&BL) & $10-30$ & Buildings and other man-made structures. \\
\hline
\end{tabular}

Note: $*$ is the abbreviation of the classes.

\subsection{Analysis of NPP Dynamic Index}

The NPP dynamic index reflects the variation trend within a certain stage. Spatial pattern of the NPP dynamic index is helpful to reflect and compare the trend in different regions. The NPP dynamic index $K$ is estimated by Equation (1):

$$
K=\frac{N P P_{b}-N P P_{a}}{N P P_{\lambda}} \times 100 \%
$$

where $N P P_{a}$ and $N P P_{b}$ are the NPP value of a certain time period at the beginning and end of the research period, respectively. $N P P_{\lambda}$ is the NPP mean value in this period.

\subsection{Effects of Changes in Weather and LULC on NPP}

NPP variations are driven by many impact factors. As illustrated in CASA model, two main input factors are weather variables and land cover data. CASA is a process-based model and appropriate to estimate NPP on a global or regional scale [13]. In the CASA model, NPP is the product of modulated absorbed photosynthetically-active radiation (APAR) and a light use efficiency factor, namely [54]: 


$$
\operatorname{NPP}(x, t)=\operatorname{APAR}(x, t) \times \varepsilon(x, t)
$$

where, $N P P(x, t)$ represents NPP in the geographic coordinate of a given location $x$ and time $t$. $\operatorname{APAR}(x, t)\left(\mathrm{MJ} \cdot \mathrm{m}^{-2} \cdot \mathrm{mon}^{-1}\right)$ is the APAR absorbed by the vegetation. $\varepsilon(x, t)$ is the actual light use efficiency $\left(\mathrm{g} \cdot \mathrm{C} \cdot \mathrm{MJ}^{-1}\right)$ of the vegetation. The algorithm of light use efficiency can be expressed as Equation (3):

$$
\varepsilon(x, t)=T_{\varepsilon 1(x, t)} \times T_{\varepsilon 2(x, t)} \times W_{\varepsilon(x, t)} \times \varepsilon_{\max }
$$

where $T_{\varepsilon 1(x, t)}$ and $T_{\varepsilon 2(x, t)}$ are temperature stress coefficients; $W_{\varepsilon(x, t)}$ is a moisture stress coefficient and $\varepsilon_{\max }$ is a biome-specific light use efficiency factor that is estimated from daily meteorological conditions. $\varepsilon_{\max }$ is the maximal light use efficiency of the specific biome under ideal conditions (minimum temperature and vapour pressure deficit) and is related to vegetation fraction and types.

The CASA ecosystem is robust in describing NPP spatial and temporal patterns [54], and can easily obtain NPP with the help of remote sensing data, but which does not take into account the physics processes of photosynthetic assimilation, respiration, and assimilate allocation [13]. On the basis of light use efficiency (LUE) and weather variables of temperature and moisture [55], inputting with the time-series NDVI data for the specific covers, and thus, the NPP variation process, can be estimated for each pattern. So, the derived LUE and NDVI data present significant differences among various vegetation types. Remote sensing data combined with basic field survey work is beneficial to obtain the accurate value for long-term monitoring of a wide area [56].

As the above stated, the effects of LULC change on NPP can be regarded as a disturbance caused by human activities in urban expansions, and the effects of climate change indicates the natural change of the ecological system. However, most studies only account for one of the two aspects [57]. In fact, the effects of changes in climate on NPP are significant, as are changes in LULC. Therefore, the main effects should consider the three contributions of LULC change, climate change and the common interactions of both [35]. The third one probably contains factors such as stand age effect, plant growth and atmosphere $\mathrm{CO}_{2}$ [58]. Considering the evergreen needleleaf forest (ENF) as an example, if $S_{1}, S_{2}$, $N P P_{1}$ and $N P P_{2}$ express the LULC area and NPP per unit area, respectively, in times $t_{1}$ and $t_{2}$, the variation of total NPP $\left(\triangle N P P_{\mathrm{T}}\right)$ should be expressed as Equation (4):

$$
\triangle N P P_{\mathrm{T}}=N P P_{2} \times S_{2}-N P P_{1} \times S_{1}=\Delta N P P \times S_{1}+\Delta S \times N P P_{1}+\Delta S \times \Delta N P P
$$

Thus, the fractional variation in $\triangle N P P_{\mathrm{T}}$ includes three parts in Equation (4): the fractional variation affected by climate change equals the first item $\left(\triangle N P P \times S_{1}\right)$, the fractional variation affected by LULC change equals the second item $\left(\triangle S \times N P P_{1}\right)$, and their common interaction term which is the last item $(\triangle N P P \times \triangle S)$. Not considering their common interactions, the following equations show the relative effects of changes in weather variables (Equation (5)) and LULC (Equation (6)) on total NPP $\left(R_{\mathrm{C}}, R_{L U L C \text { change }}\right)$.

$$
\begin{gathered}
R_{C}=\frac{\left|\Delta N P P \times S_{1}\right|}{\left|\Delta N P P \times S_{1}\right|+\left|\Delta S \times N P P_{1}\right|+|\Delta S \times \Delta N P P|} \times 100 \% \\
R_{L U L C C}=\frac{\left|\Delta S \times N P P_{1}\right|}{\left|\Delta N P P \times S_{1}\right|+\left|\Delta S \times N P P_{1}\right|+|\Delta S \times \Delta N P P|} \times 100 \%
\end{gathered}
$$




\section{Results and Discussion}

\subsection{Variation of LULC and NPP}

\subsubsection{LULC Classification and Uncertainty Processing}

The overall accuracies of 11 types classification were $82.5 \%(\mathrm{Kappa}=0.80), 81.4 \%(\mathrm{Kappa}=0.78)$ and $83.3 \%(\mathrm{Kappa}=0.81)$ for 2001, 2003 and 2006, respectively, which are, in general, sufficient to meet the monitoring accuracy demands of LULC change in Guangzhou. The classification accuracy is higher than that of MODIS 12Q1 by about 80\% [45]. According to the classification error distributions, two steps are used to reduce the effects of both errors and image noise in the NPP analysis.

(1) Considering a classification accuracy of $x$, the pixels remained within a range of $(1-x) / 2$ to $(1+x) / 2$, of which $95 \%$ of pixels are regarded as significantly normal pixels with a high accuracy.

(2) The unsatisfactory pixels that are out of the range are identified, further validated, and then rejected in the succeeding analysis process.

As a result, the comparison of NPP mean values for the two groups of pixels for the same covers led to two findings: (1) the NPP mean values of unsatisfactory pixels are greater than the normal pixels due to the misclassification; (2) the difference between the two groups is within the range of 2-10 $\mathrm{g} \cdot \mathrm{C} \cdot \mathrm{m}^{-2} \cdot \mathrm{yr}^{-1}$, and the maximum difference ratio is within $3.0 \%$ of the corresponding mean value. It is demonstrated that the classification errors have impacts and were eliminated first. At last, the classification results were subsequently re-sampled to $1 \mathrm{~km}$ resolution to cooperate with the NPP. The resample accuracy was $91.1 \%$ suggesting a good guarantee of NPP.

As shown in Figure 2, the SAM decision tree classifier map presents a more robust depiction of the vegetation-cover mosaic, and the small croplands and open shrublands throughout the woodland grasses and forests are more evident. By comparing the conversion areas from the origin cover to other areas in Figure 3, the following distinct LULC changes are obtained. (1) Evergreen coniferous forest was reduced and transformed to mixed forest and evergreen broadleaf forest during the first period and to shrublands during the latter period. (2) Evergreen broadleaf forest was mainly converted to mixed forest and woody savannas during the first and second periods, respectively. (3) Shrublands, woody savannas, and grasslands were clearly converted to croplands and cropland/vegetation mosaics during the first period. Thus, the trend of forest conversion to shrubs and woody grass was high, and a portion of the shrub and woody grass areas were subsequently reclaimed as croplands and cropland/vegetation mosaics. It is clearly evident that areas of cropland and cropland/vegetation located in suburbs surrounding the Huadu and Baiyun districts were increased by the occupation of original grasslands in 2003 and were decreased during urban expansion such that conversion to grasslands occurred again in 2006. In 2006, large areas of forests decreased in size, and certain town areas were associated with urban landscapes. There was a high conversion of forest and woody grass cover into large areas of cropland and cropland/vegetation mosaics, as shown in yellow, in the suburban areas near the Conghua, Luogang and Zengcheng districts. These changes during the initial period corresponded with the implementation of the urban development strategy in 2000 in Luogang, Conghua and Zencheng, and changes during the latter period correlated with the integration of the Nansha district into the mega-city of greater Guangzhou. 
Figure 2. Land cover/land use (LCLU) classification mapping (a) 2000, (b) 2003, (c) 2006.

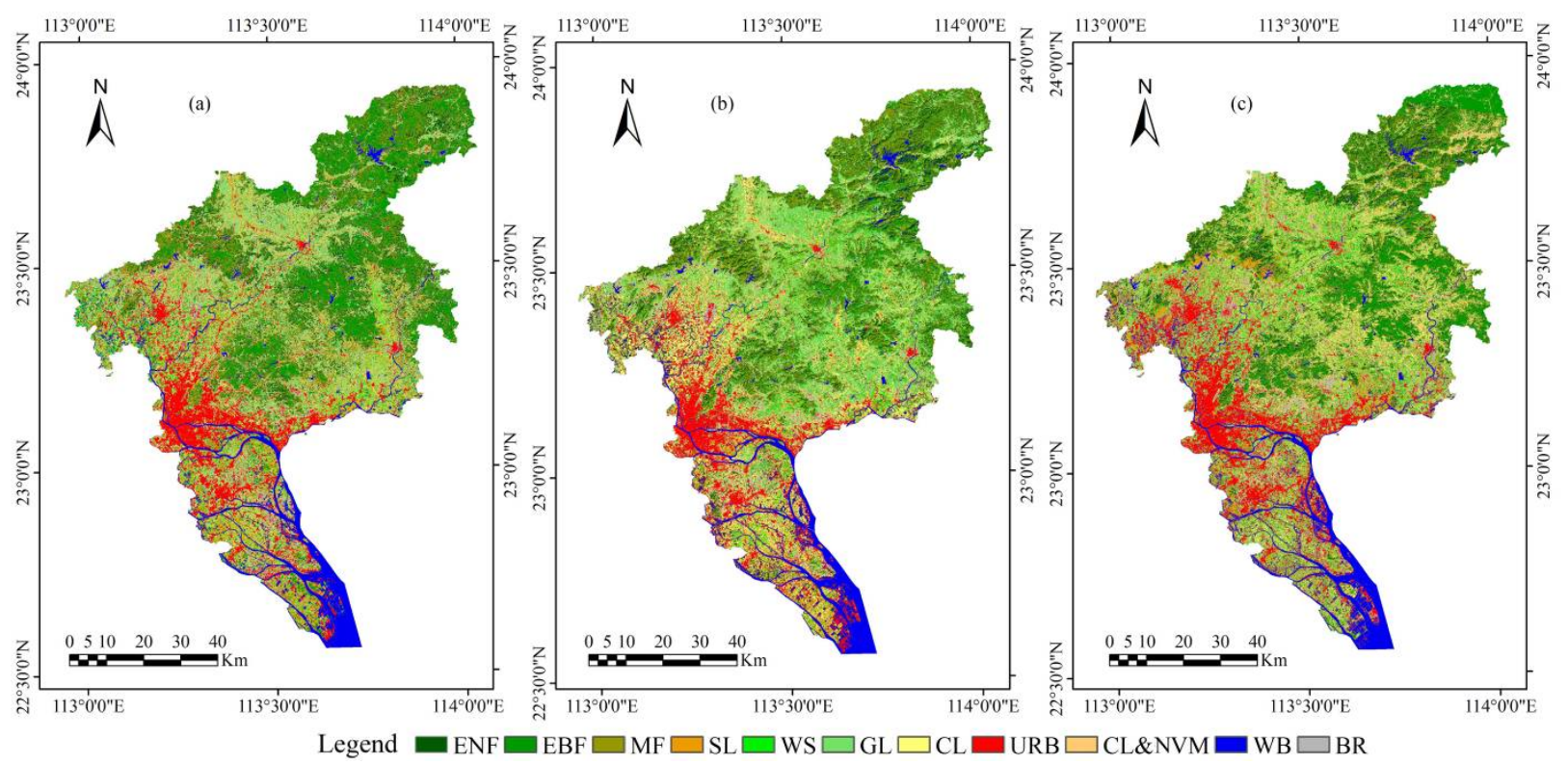

Figure 3. Conversion areas among land use/land covers during (a) 2001-2003, (b) 2003-2006.

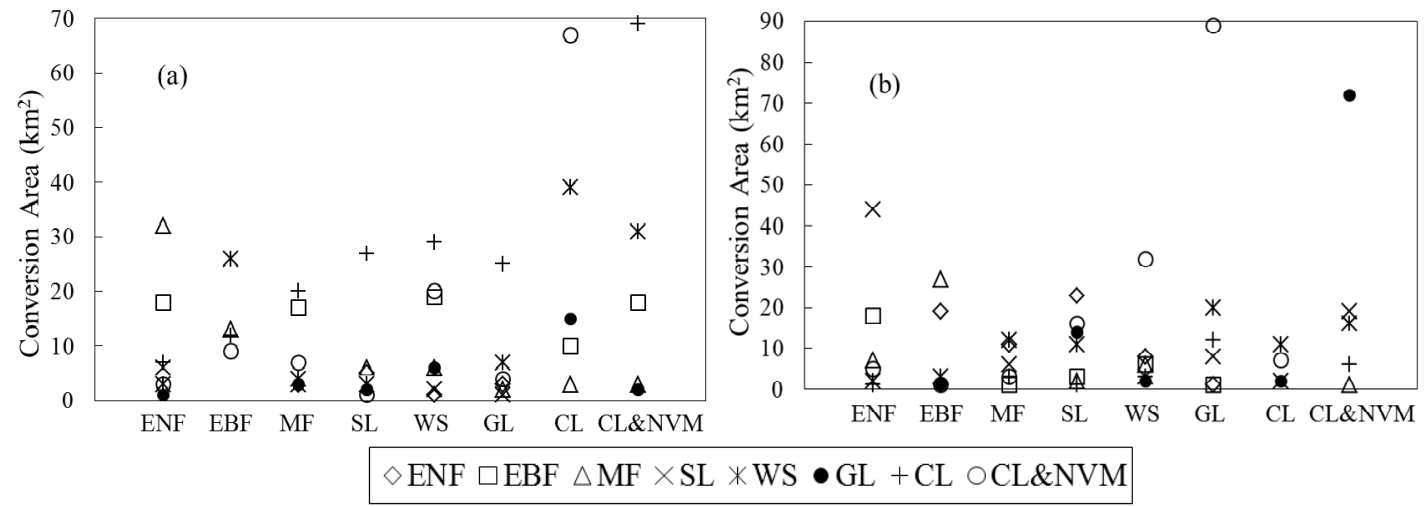

\subsubsection{Total NPP Variations against LULC}

As the above stated, LULC change can directly alter the ecological system's NPP. Investigation into total NPP variations against LULC changes is beneficial to identify the impacts on NPP quantity and structure. The statistic mean NPP values of different land covers in Guangzhou are listed in Table 2 during the two periods. Among them, the mean values of forests were higher than the average, while that of grassland were the lowest. Evergreen needleleaf forests had the lowest NPP among the three forests classes, probably due to large areas of sapling forest with lower productivity [59-61]. Introducing broadleaf to needleleaf forests to accelerate the conversion to mixed forests was an effective way to maintain a high level of regional forest NPP [59,62]. In the initial period, needleleaf forests converted into mixed forests and broadleaf forests are one case from low-NPP covers to high NPP-covers, as illustrated in Table 3, suggesting result of rising total NPP of mixed and broadleaf forests in the first period. In addition, the NPP of croplands had the largest increment of $48.4 \times 10^{6} \mathrm{gC}$ due to elevated areas, for example in the surrounding region of some districts in the 2003 classification mapping (Figure 2b). Decline in NPP mainly occurred in the destroyed needleleaf and shrublands. 
On the contrary from 2003 to 2006, many forests covers were changed into shrublands and cropland/vegetation mosaics, while the NPP did not have an obvious increase. The obvious decrease in total NPP of grasslands, needleleaf and broadleaf forests reached $79.5 \times 10^{6} \mathrm{~g} \cdot \mathrm{C}, 26.7 \times 10^{6} \mathrm{~g} \cdot \mathrm{C}$ and $22.1 \times 10^{6} \mathrm{~g} \cdot \mathrm{C}$, respectively.

Table 2. Net primary productivity (NPP) mean values of the land use/land cover types in Guangzhou.

\begin{tabular}{ccc}
\hline Code & LULC Types & NPP Mean Value $\left(\mathbf{g} \cdot \mathbf{C} \cdot \mathbf{m}^{-\mathbf{2}} \cdot \mathbf{y r}^{\mathbf{- 1}}\right)$ \\
\hline 1 & ENF & 388 \\
2 & EBF & 446 \\
3 & MF & 456 \\
4 & SL & 415 \\
5 & WS & 398 \\
6 & GL & 317 \\
7 & CL & 367 \\
9 & CL\&NVM & 373 \\
\hline
\end{tabular}

Table 3. Changes in LULC and NPP in Guangzhou from 2001 to 2006.

\begin{tabular}{|c|c|c|c|c|c|}
\hline & \multirow[b]{2}{*}{ LULC Types } & \multicolumn{2}{|l|}{ 2001-2003 } & \multicolumn{2}{|l|}{ 2003-2006 } \\
\hline & & $\begin{array}{c}\text { Variation of Total NPP } \\
\left(\times 10^{6} \mathrm{~g} \cdot \mathrm{C}\right)\end{array}$ & $\begin{array}{c}\Delta \text { Area } \\
\left(\mathbf{k m}^{2}\right)\end{array}$ & $\begin{array}{c}\text { Variation of Total NPP } \\
\left(\times 10^{6} \mathrm{~g} \cdot \mathrm{C}\right)\end{array}$ & $\begin{array}{l}\Delta \text { Area } \\
\left(\mathbf{k m}^{2}\right)\end{array}$ \\
\hline 1 & ENF & -17.0 & -58 & -26.7 & -33 \\
\hline 2 & EBF & 33.4 & 29 & -22.1 & -14 \\
\hline 3 & $\mathrm{MF}$ & 10.4 & 8 & 1.3 & 19 \\
\hline 4 & SL & -11.9 & -35 & 19.6 & 121 \\
\hline 5 & WS & 5.3 & 30 & -3.2 & 6 \\
\hline 6 & GL & -6.6 & -19 & -79.5 & -173 \\
\hline 7 & CL & 48.4 & 55 & 2.7 & 25 \\
\hline 9 & CL \& NVM & 5.0 & -12 & 8.0 & 94 \\
\hline
\end{tabular}

In general, the reduction of total NPP was mainly from the contribution of needleleaf and broadleaf forests, shrublands and grasslands, which had most conversion areas to croplands. With urban expansion and rapid economic development, as depicted in Figure 2c, LULC changes mainly displayed from high cove forests to croplands in suburb and exurb areas such as Luogang, conghua and Zengcheng districts. This process led to an increase in land fragmentation and a decrease in NPP until it reached present state. It is reported that the urban expansion mechanism will inevitably lead to reduction of the surrounding land covers, such as the common croplands, grasslands, shrublands, etc. Then, the further land reclamation in exurb would be used to balance the structure of croplands [63,64]. These variations should be visible in the following spatial-temporal dynamics under the LULC changes.

\subsection{NPP Spatiotemporal Variation}

NPP mean value of Guangzhou changed from $331.5 \mathrm{~g} \cdot \mathrm{C} \cdot \mathrm{m}^{-2} \cdot \mathrm{yr}^{-1}$ in 2001 to $366.3 \mathrm{~g} \cdot \mathrm{C} \cdot \mathrm{m}^{-2} \cdot \mathrm{yr}^{-1}$ in 2003, and then to $273.2 \mathrm{~g} \cdot \mathrm{C} \cdot \mathrm{m}^{-2} \cdot \mathrm{yr}^{-1}$ in 2006 , and standard deviation is $10.2,18.3$ and $22.6 \mathrm{~g} \cdot \mathrm{C} \cdot \mathrm{m}^{-2} \cdot \mathrm{yr}^{-1}$, respectively. It increased by mean value of $34.8 \mathrm{~g} \cdot \mathrm{C} \cdot \mathrm{m}^{-2}$ during the first three years and dropped fast 
by $93.1 \mathrm{~g} \cdot \mathrm{C} \cdot \mathrm{m}^{-2}$ during the last three years. The NPP obvious changes during the fast urbanization period is consistent with the study of $\mathrm{Hu}$ [29]. A related study reported on the alternating effects of La Niña and El Niño on climate change during 1950-2005 [46]. By investigating the impacts of ENSO in Guangzhou, the positive correlation between the Nino3.4 Sea Surface Temperature (SST) index and monthly weather variables of temperature and precipitation using a significant $t$ test suggested that ENSO had a clear effect on the meteorology variables. For Guangzhou, 2001 was a weak La Niña year, 2003 was a strong El Niño year, and 2005 was a weak El Niño year [65]. Thus, the rapid urbanisation accompanied by a short-term alteration of ENSO events, which have a boundary point in 2003, corresponds with an increasing NPP trend during the first period (2001-2003) and a decreasing trend during the latter period (2003-2006), as shown in Figure 4a.

Figure 4. (a) NPP variation trend, (b) statistical histogram of the NPP dynamic indexes, spatial mapping in (c) 2001-2003 and (d) 2003-2006.
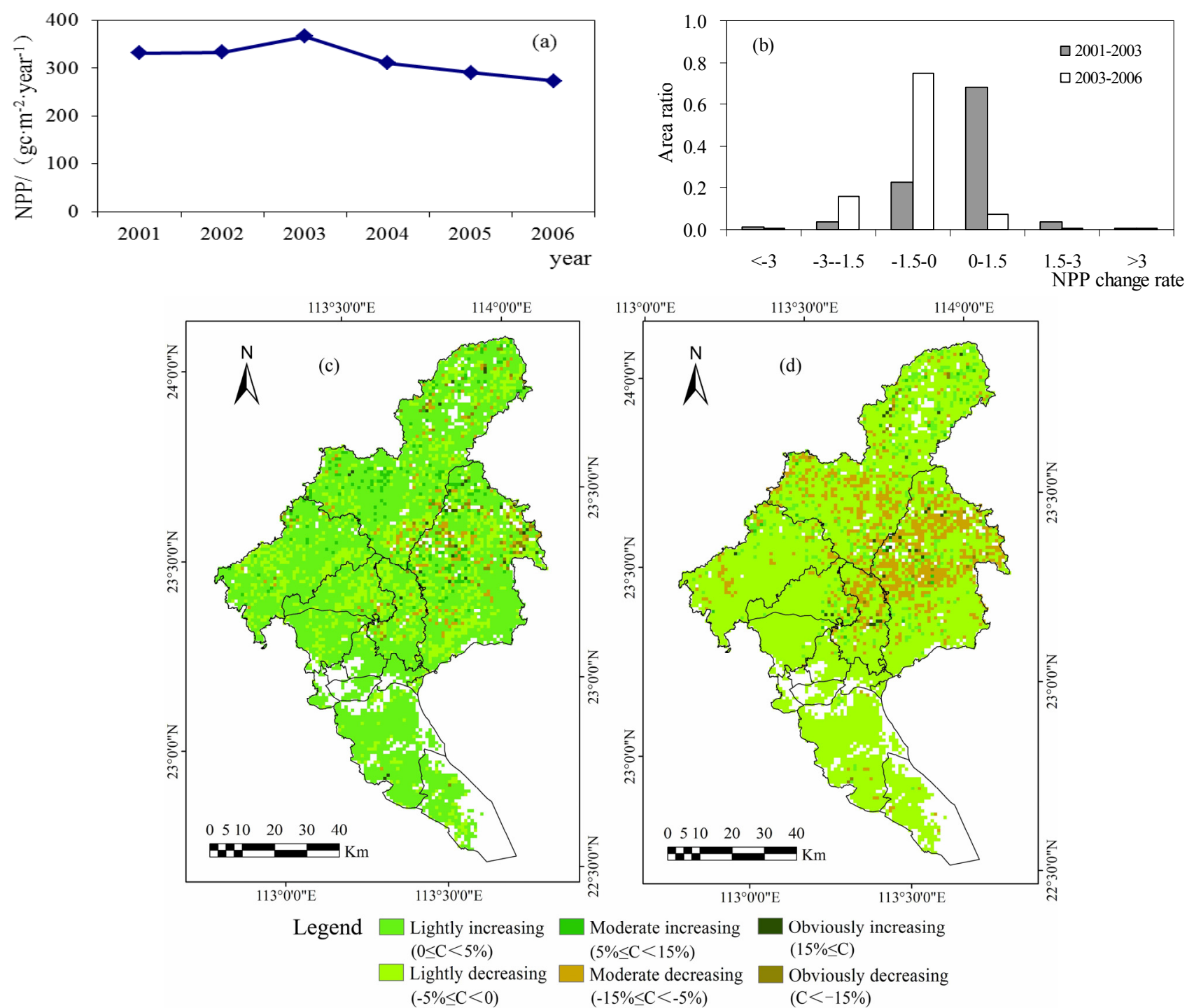

As illustrated in Figure 4, variations in NPP including the increasing and decreasing trends, were divided into three levels according to the dynamic index: slight change $(|0 \%-5 \%|)$, moderate change $(|5 \%-15 \%|)$ and obvious change $(>|15 \%|)$, as shown in the statistical histogram (Figure $4 \mathrm{~b})$. During the 
initial period, the NPP of $68 \%$ of pixels had a light growth rate of $0 \%-5 \%$, while a light to moderate reduction of NPP occurred in the central suburb, and central exurb of Guangzhou. During the latter period (Figure $4 \mathrm{~d}$ ), the NPP of $74.6 \%$ of pixels in most parts of Guangzhou had a lightly decreasing trend $(-5 \%-0 \%)$, and pixels that had a moderate to obvious decreasing trend occurred in the central suburb and the edge between the suburb and the exurb. In addition, the pattern of declining NPP obviously expanded from the suburb to the exurb and expanded from the central exurb to the north exurb. Meanwhile, the NPP dynamic index of decline varied from light to moderate in these regions.

Liu [59] pointed out that temporal dynamics of NPP in Guangzhou belonged to a stable type in 1981-2000, but there has been a downward trend from 1991 to 2000. Belonging to increasing type cities, the NPP increasing rate of Jieyang and Shanwei was 39 and $45 \mathrm{~g} \cdot \mathrm{C} \cdot \mathrm{m}^{-2}$ per five years, respectively, in 1981-2000. On the contrary, NPP of the surrounding region Foshan, Shenzhen and Dongguan decreased by 114,87 and $75 \mathrm{~g} \cdot \mathrm{C} \cdot \mathrm{m}^{-2}$ per five years, respectively, in 1991-2000. This is basically in accordance with our study in Guangzhou.

\subsection{Effects of Changes in Weather and LULC}

Using Equations (5) and (6), the effects of changes in weather and LULC on the NPP of eight land covers were calculated. The average values for effects of weather and LULC change were 0.43 and 0.51, respectively, in 2001-2003, and were 0.45 and 0.48, respectively, in 2003-2006. There were contributions of common interactions for both effects of about 0.06 and 0.07 during the two periods. As stated above, ENSO events clearly affected the weather meteorology variables and thus, impacted the NPP in Guangzhou as well as the global NPP [46]. Despite the overall effects of climate conditions, the effect of the LULC was greater than that of weather variations during both periods, suggesting the significance of LULC as a driving force. Spatial correlation and cluster methods have been used to analyse the quantity and spatial patterns caused by the driving effects at three levels corresponding to slight, moderate and strong variations. A combination of NPP dynamic index and the concerned effects revealed the mechanism of the LULC effects shown in Figure 5. Moreover, the results clearly demonstrated the spatial relationship of the NPP variation response with the driving force at different intensities. As illustrated in Figure 6, obvious spatial cluster scopes and the trend of NPP variation appears in the central area, suburb and exurb under three driving patterns including weather variation dominated, LULC change dominated, and interaction of both effects.

The results show that four categories of effects of weather and LULC variation, divided by the area ratio of three levels, show different impacts in the central area, suburb and exurb. When the two effects were under $25 \%$ (Figure $5 \mathrm{a}$ ), both caused similar area ratio $(\sim 68 \%)$ of NPP slight change which indicates the interactive effects of both slightly affects NPP. Most areas of NPP had a light fluctuation within range of $-5 \%$ to $5 \%$. Moreover, when the relative effects varied between $25 \%$ and $40 \%$ (Figure 5b), the NPP area ratio influenced by weather variation during the two periods were $15.1 \%$ $\left(\sim 1,120 \mathrm{~km}^{2}\right)$ and $27.8 \%\left(\sim 2,061 \mathrm{~km}^{2}\right)$, respectively, while area ratio affected by LULC change were less than $10 \%$. Therefore, weather variation within range of $25 \%-40 \%$ played a weather-dominated role. NPP dynamic index also focused between $-5 \%$ and $5 \%$. A similar condition was observed when the relative effects were more than $85 \%$ (Figure $5 \mathrm{~d}$ ). It was demonstrated that a slight fluctuation in larger areas caused by interactive effects or the weather-dominated effects was common. As shown in 
Figure 6, spatial patterns of these areas were weather in the border between suburb and exurb, and with the passage of time, the influence scope was wider in suburb as opposed to that in exurb.

Figure 5. Statistical histogram of NPP dynamic index within the different scopes of effects. (a) $0 \%-25 \%$. (b) $25 \%-40 \%$. (c) $40 \%-85 \%$. (d) $85 \%-100 \%$. (1) 2001-2003 weather variation. (2) 2001-2003 LULC change. (3) 2003-2006 weather variation. (4) 2003-2006 LULC change.
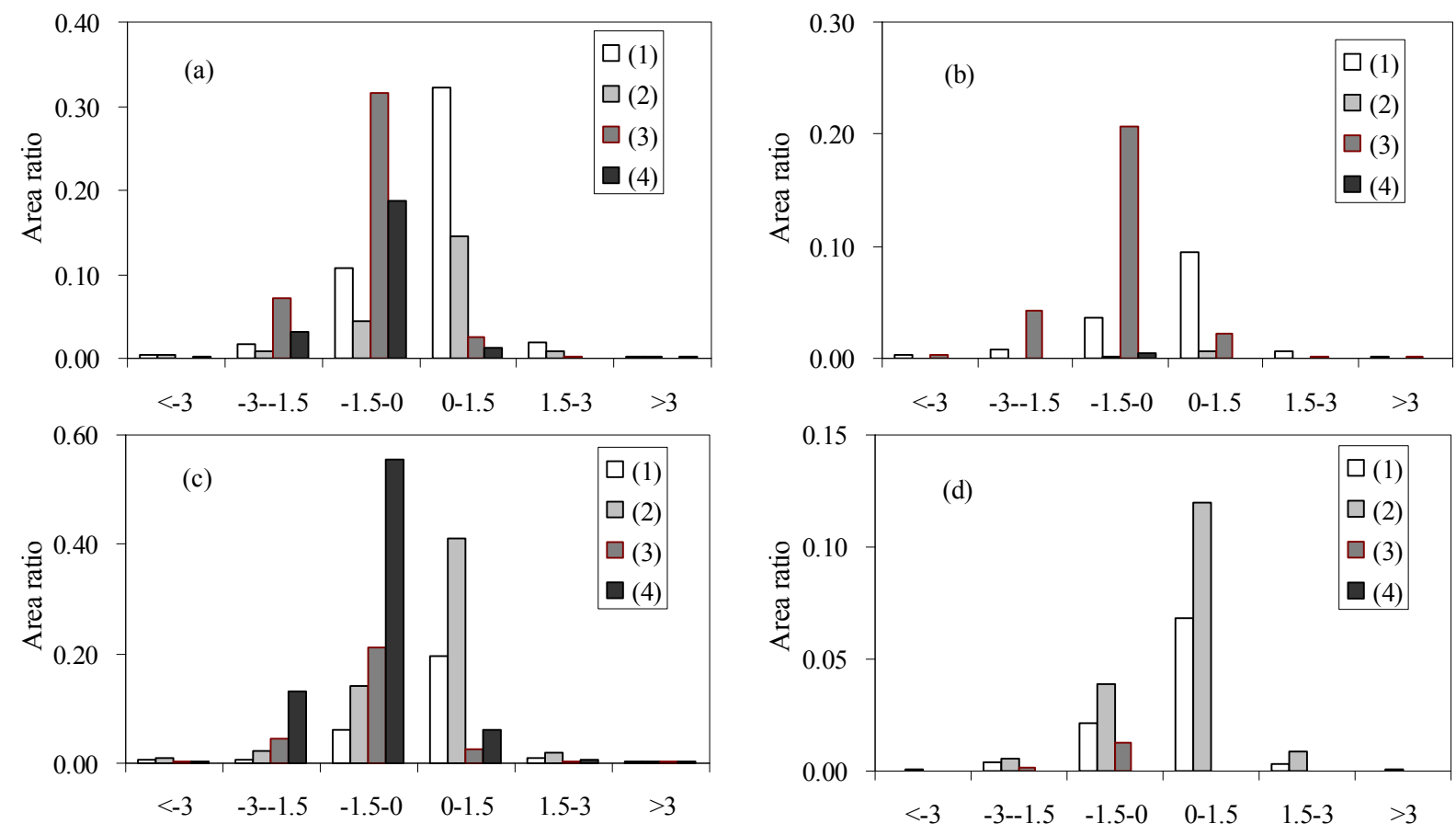

When the effects dropped into the $40 \%-85 \%$ range (Figure $5 \mathrm{c}$ ), NPP affected by LULC change mainly had a lightly increasing and decreasing trend with the area ratio about $67.8 \%$ and $73.1 \%$ during both two periods, respectively. So, the effects within the $40 \%-85 \%$ range were mainly dominated by LULC change. These variations obviously assembled in the suburb in the initial period (Figure 6b), and then in the exurb in the latter period (Figure 6d). The distinct development from the suburb to exurb was consistent with the urban sprawl trend. In this outward process as shown in Figure 2c, LULC change in some areas of the exurb caused NPP degradation from the slight decreasing (ratio of $-5 \%-0$ ) to the moderate decreasing (ratio of $-15 \% \sim-5 \%$ ) during the two periods.

In general, the decrease of NPP suggested the land degradation, while the increase of NPP reflected the vegetation restoration $[15,30,38]$. Therefore, with the effects being varied within $25 \%-40 \%$, weather variation played the main role in NPP and mainly caused slight land degradation in the suburb in the early stage. LULC change with its effects above $40 \%$ dominated the results that the obvious land degradation happened from the suburb to the exurb in the urban outward expansion. As the above stated, the main land cover types around urban such as croplands, grasslands, shrublands and even forests, were gradually taken for the urban sprawl, and then supplemented the loss of croplands. In the LULC change perspective, ENF, EBF, SL and GL had large conversion areas to CL. This conversion case from high-NPP covers to low-NPP covers directly causes reduction of NPP. Although a temporary slight increase of NPP occurred in the early stages, the conversion from other vegetation 
types to urban and croplands strengthened human disturbance and ultimately led to obvious land degradation in the latter period.

Figure 6. Spatial mapping of three effects patterns in the central area, suburb and exurb. (a) 2001-2003 weather variation. (b) 2001-2003 LULC change. (c) 2003-2006 weather variation. (d) 2003-2006 LULC change.
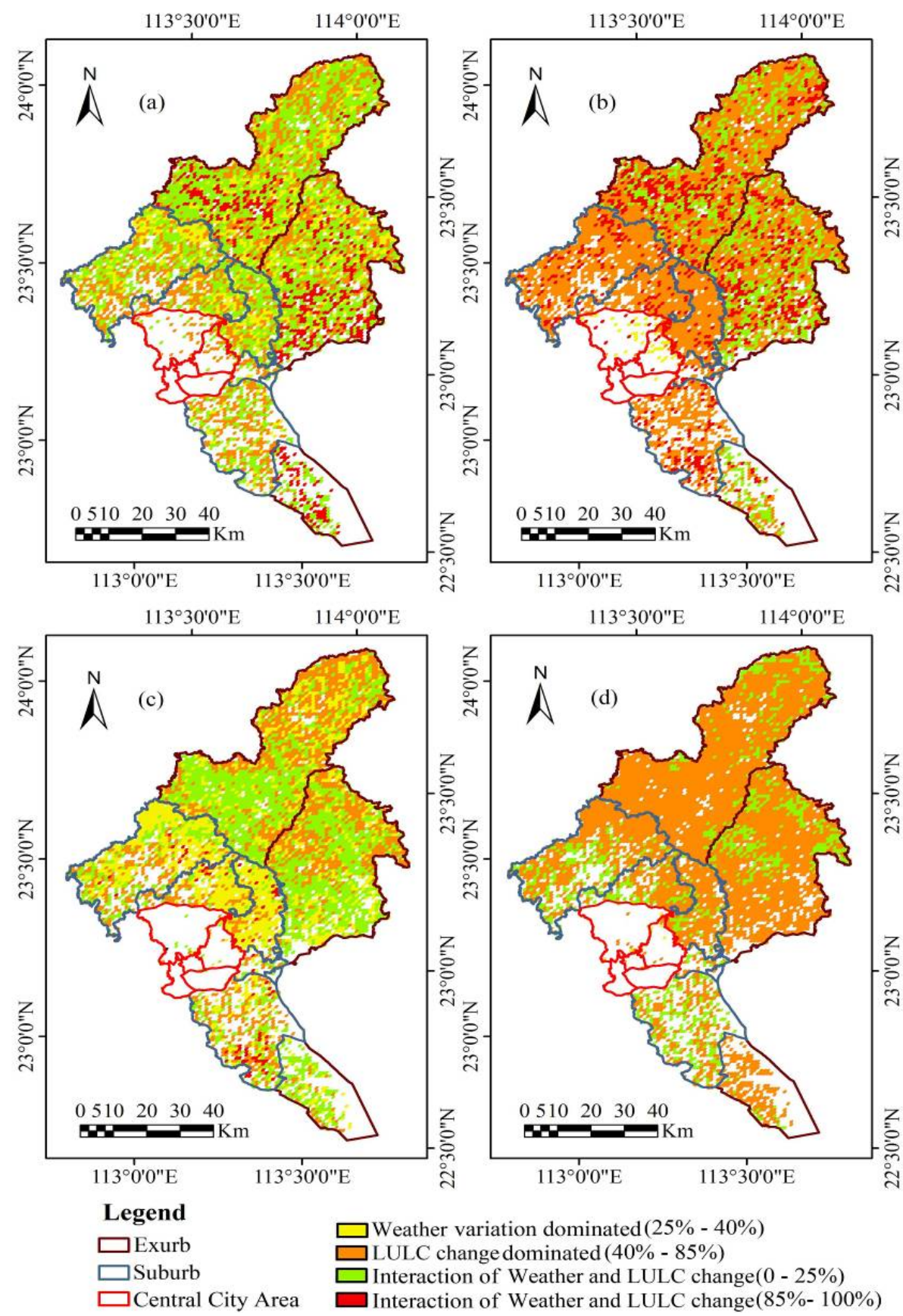

\subsection{Weather Variations}

The average annual temperature and annual total precipitation of Guangzhou are shown in Figure 7, which indicates that the temperature fluctuation was stable and smaller than the precipitation fluctuation. It is demonstrated by variations of monthly temperature and total precipitation in Figure 7 , and precipitation reached the bottom in 2003 and then increased significantly. NPP change had a 
positive correlation with temperature and a negative correlation with precipitation, and the correlation coefficient between temperatures, precipitation was higher in the latter period than in the early period (Table 4). It is probably a lag NPP response to the strong El Niño event in 2003. The highest negative correlation coefficient between precipitation and NPP occurred in the suburb, and the weak relation occurred in the central and exurb during both periods. However, from 2001 to 2003, the correlation coefficient was only -0.27 with standard deviation 0.46 , and it reached to -0.85 with standard deviation only 0.14 from 2003 to 2006 . The correlation coefficient suggested that the relationship between precipitation and NPP was more closed in the large suburb area during the latter period, which was consistent with the effects dominated by weather variation.

Figure 7. Annual average temperature and total precipitation in Guangzhou from 2000 to 2007.

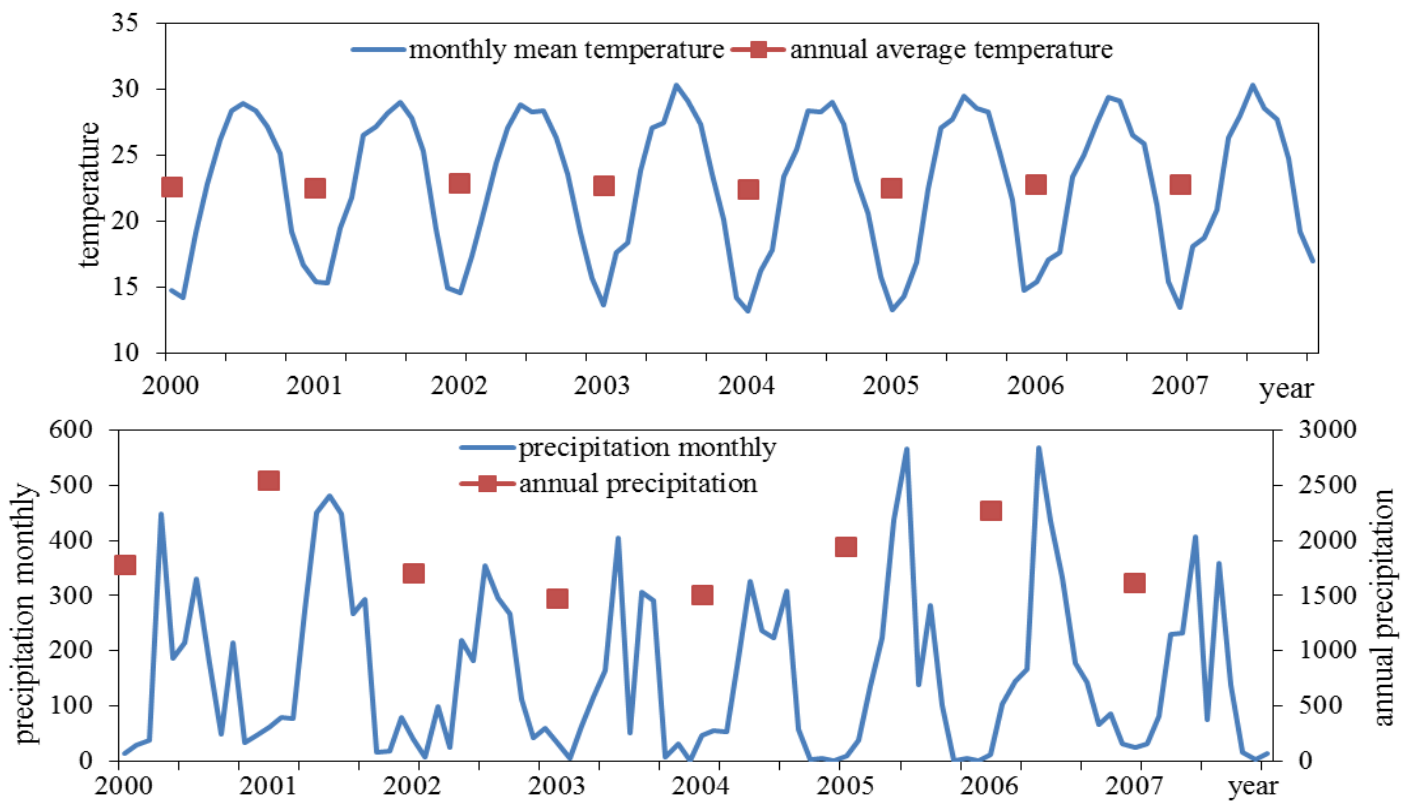

Table 4. Correlations between NPP and temperature and precipitation.

\begin{tabular}{|c|c|c|c|c|c|c|c|c|}
\hline & \multicolumn{4}{|c|}{ 2001-2003 } & \multicolumn{4}{|c|}{ 2003-2006 } \\
\hline & \multicolumn{2}{|c|}{ NPP-Temperature } & \multicolumn{2}{|c|}{ NPP-Precipitation } & \multicolumn{2}{|c|}{ NPP-Temperature } & \multicolumn{2}{|c|}{ NPP-Precipitation } \\
\hline & Average & SD (*) & Average & SD & Average & SD & Average & SD \\
\hline Central Area & 0.13 & 0.55 & -0.19 & 0.55 & 0.74 & 0.33 & -0.63 & 0.36 \\
\hline Suburb & 0.19 & 0.45 & -0.27 & 0.46 & 0.84 & 0.25 & -0.85 & 0.14 \\
\hline Exurb & 0.18 & 0.68 & -0.21 & 0.67 & 0.34 & 0.47 & -0.63 & 0.38 \\
\hline
\end{tabular}

Note: $\mathrm{SD}(*)$ is the standard deviation.

\section{Conclusions}

From the perspective of urban expansion, NPP was used to discover the spatiotemporal pattern variation of urban carbon storage and its driving mechanisms. To achieve this purpose, the current study replaced complex physiological parameters in the ecological models with a comparison between the effects of weather variations and LULC changes on NPP. An evaluation based on this method can not only identify the entire trend of weather variations and natural ecosystems, but it also estimates the NPP response to different effect patterns caused by urbanisation. Future work should further explore 
how conversion of LULC can determine intensity and magnitude of the effects. The next step will be further assessment in relation to LULC change with ability for GHG reduction in urban areas, based on the study conclusions:

During the fast urban expansion and adjustment period, the NPP mean value reached $331.5 \mathrm{~g} \cdot \mathrm{C} \cdot \mathrm{m}^{-2} \cdot \mathrm{a}^{-1}$ in $2001,366.3 \mathrm{~g} \cdot \mathrm{C} \cdot \mathrm{m}^{-2} \cdot \mathrm{a}^{-1}$ in 2003 and changed to $273.2 \mathrm{~g} \cdot \mathrm{C} \cdot \mathrm{m}^{-2} \cdot \mathrm{a}^{-1}$ in 2006 . The spatiotemporal pattern of NPP variations was distinct in the central area, suburb and exurb, which was caused by both effects with different intensities. Combined with the NPP variation response, the four intensity categories were divided into three driving patterns, including the interactive influences of both effects (effect intensity $<25 \%$ or $>85 \%$ ), effects dominated by weather variations (effect intensity of $25 \%-40 \%$ ) and effects dominated by LULC changes (effect intensity of $40 \%-85 \%$ ). The previous two patterns mainly led to a slight and common fluctuation in the central urban and the suburb; while the third pattern was the main driving force causing the fast reduction of NPP in some areas of the suburb and exurb. Importantly, this study revealed that the conversion from grassland, shrubland and forest cover to urban areas and croplands corresponds to a change from high-NPP coverage to low-NPP coverage. So, the conversion case strengthened human disturbance and ultimately led to fast degradation of carbon stocks ability. The total decreased NPP was about $167 \times 10^{6} \mathrm{~g} \cdot \mathrm{C}$ during this fast urbanization period.

\section{Acknowledgments}

This work was supported by the National Natural Science Foundation of China (No. 41101152, No. 40901090), the Scientific Research Foundation for the Returned Overseas Chinese Scholars, State Education Ministry, the talents introduced into Universities Foundation of Guangdong Province of China,the China Scholarship Council (CSC) funding 2013, and the universities disciplinary and special construction funds of Guangdong Province Foundation (C10092), the Scientific Research Foundation of Graduate School of South China Normal University.

\section{Conflicts of Interest}

The authors declare no conflict of interest.

\section{References}

1. Cifuentes, L.; Borja-Aburto, V.H.; Gouveia, N.; Thurston, G.; Davis, D.L. Assessing the health benefits of urban air pollution reductions associated with climate change mitigation (2000-2020): Santiago, Sao Paulo, Mexico City, and New York City. Environ. Health Perspect. 2001, 109, 419-425.

2. Patz, J.A.; Campbell-Lendrum, D.; Holloway, T.; Foley, J.A. Impact of regional climate change on human health. Nature 2005, 438, 310-317.

3. Bell, M.L.; Goldberg, R.; Hogrefe, C.; Kinney, P.L.; Knowlton, K.; Lynn, B.; Rosenthal, J.; Rosenzweig, C.; Patz, J.A. Climate change, ambient ozone, and health in 50 US cities. Clim. Chang. 2007, 82, 61-76. 
4. Younger, M.; Morrow-Almeida, H.R.; Vindigni, S.M.; Dannenberg, A.L. The built environment, climate change, and health: Opportunities for co-benefits. Am. J. Prev. Med. 2008, 35, 517-526.

5. Crabtree, R.; Potter, C.; Mullen, R.; Sheldon, J.; Huang, S.; Harmsen, J.; Rodman, A.; Jean, C. A modeling and spatio-temporal analysis framework for monitoring environmental change using NPP as an ecosystem indicator. Remote Sens. Environ. 2009, 113, 1486-1496.

6. Milner, J.; Davies, M.; Wilkinson, P. Urban energy, carbon management (low carbon cities) and co-benefits for human health. Curr. Opin. Environ. Sustain. 2012, 4, 398-404.

7. Song, D.; Su, M.; Yang, J.; Chen, B. Greenhouse gas emission accounting and management of low-carbon community. Sci. World J. 2012, 2012, doi: http://dx.doi.org/10.1100/2012/613721.

8. Dhakal, S. Energy Use and $\mathrm{CO}_{2}$ Emissions in Cities and Future Challenges. In Urban Energy Use and Greenhouse Gas Emissions in Asian Mega-Cities; Institute for Global Environmental Strategies: Kitakyushu, Japan, 2004; pp. 43-52.

9. Lin, J.; Cao, B.; Cui, S.; Wang, W.; Bai, X. Evaluating the effectiveness of urban energy conservation and GHG mitigation measures: The case of Xiamen city, China. Energy Policy 2010, $38,5123-5132$.

10. Bolund, P.; Hunhammar, S. Ecosystem services in urban areas. Ecol. Econ. 1999, 29, 293-301.

11. Pataki, D.E.; Carreiro, M.M.; Cherrier, J.; Grulke, N.E.; Jennings, V.; Pincetl, S.; Pouyat, R.V.; Whitlow, T.H.; Zipperer, W.C. Coupling biogeochemical cycles in urban environments: Ecosystem services, green solutions, and misconceptions. Front. Ecol. Environ. 2011, 9, 27-36.

12. Group on Earth Observations. Forest Carbon Tracking Portal. Avaiable online: http://www.geo-fct.org/ (accessed on 23 April 2013).

13. Ruimy, A.; Saugier, B.; Dedieu, G. Methodology for the estimation of terrestrial net primary production from remotely sensed data. J. Geophys. Res.-Atmos. 1994, 99, 5263-5283.

14. Lieth, H. Modeling the Primary Productivity of the World. In Primary Productivity of the Biosphere; Springer: Berlin/Heidelberg, Germany, 1975; pp. 237-263.

15. Zhang, C.; Wang, X.; Li, J.; Hua, T. Roles of climate changes and human interventions in land degradation: A case study by net primary productivity analysis in China's Shiyanghe Basin. Environ. Earth Sci. 2011, 64, 2183-2193.

16. Field, C.B.; Behrenfeld, M.J.; Randerson, J.T.; Falkowski, P. Primary production of the biosphere: Integrating terrestrial and oceanic components. Science 1998, 281, 237-240.

17. Peng, D.L.; Huang, J.F.; Huete, A.R.; Yang, T.M.; Gao, P.; Chen, Y.C.; Chen, H.; Li, J.; Liu, Z.Y. Spatial and seasonal characterization of net primary productivity and climate variables in southeastern China using MODIS data. J. Zhejiang Univ. Sci. B 2010, 11, 275-285.

18. Piao, S.; Fang, J.; Guo, Q. Terrestrial net primary production and its spatio-temporal patterns in China during 1982-1999. Acta Sci. Naturalium-Univ. Pekin. 2001, 37, 563-569.

19. Sun, R.; Zhu, Q.J. Distribution and seasonal change of net primary productivity in China from April, 1992 to March, 1993 (In Chinese). Acta Geogr. Sin. 2000, 55, 36-45.

20. Chiew, F.; Whetton, P.; McMahon, T.; Pittock, A. Simulation of the impacts of climate change on runoff and soil moisture in Australian catchments. J. Hydrol. 1995, 167, 121-147.

21. Schreider, S.Y.; Jakeman, A.; Pittoc, A.; Whetton, P. Estimation of possible climate change impacts on water availability, extreme flow events and soil moisture in the Goulburn and Ovens Basins, Victoria. Clim. Chang. 1996, 34, 513-546. 
22. Liu, J.H.; Gao, J.X. Effects of climate and land use change on the changes of NPP in the farming-pastoral ecotone of Northern China (In Chinese). Resour. Sci. 2009, 31, 493-500.

23. Wen, J.S.; Ge, Y.; Jiao, L.; Deng, Z.P.; Peng, C.H.; Chang, J. Does urban land use decrease carbon sequestration? A case study in Taizhou, China (In Chinese). Chin. J. Plant Ecol. 2010, 34, 651-660.

24. Zhou, T.; Shi, P.J. Indirect impacts of land use change on soil organic carbon change in China (In Chinese). Adv. Earth Sci. 2006, 21, 138-143.

25. Pei, F.; Li, X.; Liu, X.; Wang, S.; He, Z. Assessing the differences in net primary productivity between pre-and post-urban land development in China. Agric. For. Meteorol. 2013, 171, 174-186.

26. Xiao, T.; Wang, J.B.; Chen, Z.Q. Vulnerability of grassland ecosystems in the Sanjiangyuan region based on NPP. Resour. Sci. 2010, 32, 323-330.

27. Zaehle, S.; Bondeau, A.; Carter, T.R.; Cramer, W.; Erhard, M.; Prentice, I.C.; Reginster, I.; Rounsevell, M.D.A.; Sitch, S.; Smith, B.; et al. Projected changes in terrestrial carbon storage in Europe under climate and land-use change, 1990-2100. Ecosystems 2007, 10, 380-401.

28. Core Writing Team; Pachauri, R.K.; Reisinger, A. Climate Change 2007: Synthesis Report; IPCC: Geneva, Switzerland, 2008; pp. 3-22.

29. Hu, Y.; Jia, G.; Guo, H. Linking primary production, climate and land use along an urban-wildland transect: A satellite view. Environ. Res. Lett. 2009, 4, doi: 10.1088/1748-9326/4/4/044009.

30. Wessels, K.J.; Prince, S.D.; Malherbe, J.; Small, J.; Frost, P.E.; VanZyl, D. Can human-induced land degradation be distinguished from the effects of rainfall variability? A case study in South Africa. J. Arid Environ. 2007, 68, 271-297.

31. Ren, Z.; Zhu, H.; Shi, H.; Liu, X. Spatio-temporal distribution pattern of vegetation net primary productivity and its response to climate change in Buryatiya Republic, Russia. J. Resour. Ecol. 2011, 2, 257-265.

32. Imhoff, M.L.; Bounoua, L.; DeFries, R.; Lawrence, W.T.; Stutzer, D.; Tucker, C.J.; Ricketts, T. The consequences of urban land transformation on net primary productivity in the United States. Remote Sens. Environ. 2004, 89, 434-443.

33. Lu, D.; Xu, X.; Tian, H.; Moran, E.; Zhao, M.; Running, S. The effects of urbanization on net primary productivity in southeastern China. Environ. Manag. 2010, 46, 404-410.

34. Yu, D.; Shao, H.; Shi, P.; Zhu, W.; Pan, Y. How does the conversion of land cover to urban use affect net primary productivity? A case study in Shenzhen city, China. Agric. For. Meteorol. 2009, 149, 2054-2060.

35. Hicke, J.A.; Lobell, D.B.; Asner, G.P. Cropland area and net primary production computed from 30 years of USDA agricultural harvest data. Earth Interact. 2004, 8, 1-20.

36. Gao, Z.Q.; Liu, J.Y.; Cao, M.K.; Li, K.R.; Tao, B. Impacts of land use and climate change on regional net primary productivity. Acta Geogr. Sin. 2004, 59, 581-591.

37. Xu, X.B.; Yang, G.S.; Li, H.P. Impacts of land use change on net primary productivity in the Taihu Basin, China. Resour. Sci. 2011, 33, 1940-1947.

38. Xu, D.Y.; Kang, X.W.; Liu, Z.L.; Zhuang, D.F.; Pan, J.J. Assessing the relative role of climate change and human activities in sandy desertification of Ordos region China. Sci. China Ser. D Earth Sci. 2009, 52, 855-868. 
39. Weng, Q. Land use change analysis in the Zhujiang Delta of China using satellite remote sensing, GIS and stochastic modelling. J. Environ. Manag. 2002, 64, 273-284.

40. Gong, J.Z.; Liu, Y.S.; Zhang, L. The optimal allocation of land use and its potential appraisal in Guangzhou city. Acta Geogr. Sin. 2010, 65, 1391-1400.

41. Guangzhou Yearbook Compilation Committee. Administrative Division and Weather. In Guangzhou Yearbook (In Chinese); Guangzhou Yearbook Press: Guangzhou, China, 2010; Chapter 1, pp. 4-5.

42. Local Chronicles Compilation Committee of Guangzhou. Natural Geography. In Annals of Guangzhou (In Chinese); Guangzhou Press: Guangzhou, China, 1998; Volume 2, pp. 42-49.

43. Numerical Terradynamic Simulation Group. Modeling and Monitoring Ecosystem Function at Multiple Scales. Available online: http://www.ntsg.umt.edu (accessed on 19 May 2009).

44. MODIS Science Data Support Team. Available online: http://modis-sdst.gsfc.nasa.gov (accessed on 23 September 2004).

45. Strahler, A.; Friedl, M.; Zhang, X.; Hodges, J.; Cooper, C.; Baccini, A. The MODIS Land Cover and Land Cover Dynamics Products. Presented at Remote Sensing of the Earth's Environment from TERRAQ, L'Aquila, Italy, 29 August 2002.

46. Zhang, Y.; Xu, M.; Chen, H.; Adams, J. Global pattern of NPP to GPP ratio derived from MODIS data: Effects of ecosystem type, geographical location and climate. Glob. Ecol. Biogeogr. 2009, $18,280-290$.

47. Zhao, M.; Heinsch, F.A.; Nemani, R.R.; Running, S.W. Improvements of the MODIS terrestrial gross and net primary production global data set. Remote Sens. Environ. 2005, 95, 164-176.

48. Turner, D.P.; Ritts, W.D.; Cohen, W.B.; Gower, S.T.; Running, S.W.; Zhao, M.; Costa, M.H.; Kirschbaum, A.A.; Ham, J.M.; Saleska, S.R. Evaluation of MODIS NPP and GPP products across multiple biomes. Remote Sens. Environ. 2006, 102, 282-292.

49. Kruse, F.; Lefkoff, A. Knowledge-based geologic mapping with imaging spectrometers. Remote Sens. Rev. 1994, 8, 3-28.

50. Guangzhou Meteorological Bureau Station Map. Available online: http://www.gz121.gov.cn/ (accessed on 26 August 2006).

51. Shen, H.F.; Zhong, Y.F.; Wang, Y.; Jin, S.Y.; Cao, L.Q.; Tian, X.; Yuan, Q.Q.; Jin, Y.L. Hyperspectral Image Processing. In ENVI Remote Sensing Image Processing Method (In Chinese); Wuhan University Press: Wuhan, China, 2009; pp. 213-270.

52. Nangendo, G.; Skidmore, A.K.; van Oosten, H. Mapping East African tropical forests and woodlands-A comparison of classifiers. ISPRS J. Photogramm. 2007, 61, 393-404.

53. Strahler, A.; Muchoney, D.; Borak, J.; Friedl, M.; Gopal, S.; Lambin, E.; Moody, A. MODIS Land Cover Product, Algorithm Theoretical Basis Document (ATBD), Version 5.0.; Boston University: Boston, MA, USA, 1999.

54. Potter, C.S.; Randerson, J.T.; Field, C.B.; Matson, P.A.; Vitousek, P.M.; Mooney, H.A.; Klooster, S.A. Terrestrial ecosystem production: A process model based on global satellite and surface data. Glob. Biogeochem. Cy. 1993, 7, 811-841.

55. Field, C.B.; Randerson, J.T.; Malmström, C.M. Global net primary production: Combining ecology and remote sensing. Remote Sens. Environ. 1995, 51, 74-88. 
56. Li, A.; Bian, J.; Lei, G.; Huang, C. Estimating the maximal light use efficiency for different vegetation through the CASA Model combined with time-series remote sensing data and ground measurements. Remote Sens. 2012, 4, 3857-3876.

57. Wang, H.; Li, X.; Long, H.; Gai, Y.; Wei, D. Monitoring the effects of land use and cover changes on net primary production: A case study in China's Yongding River basin. For. Ecol. Manag. 2009, 258, 2654-2665.

58. Govind, A.; Chen, J.M.; Bernier, P.; Margolis, H.; Guindon, L.; Beaudoin, A. Spatially distributed modeling of the long-term carbon balance of a boreal landscape. Ecol. Model. 2011, 222, 2780-2795.

59. Liu, H.G.; Tang, X.L.; Zhou, G.Y.; Liu, S.G. Spatial and temporal patterns of net primary productivity in the duration of 1981-2000 in Guangdong, China (In Chinese). Acta Ecol. Sin. 2007, 27, 4065-4074.

60. Tan, B.C. Analysis of the crux of guangdong forestry construction in Guangdong (In Chinese). For. China 1999, 12, 37.

61. Lu, Z.X.; Deng, W.S. Problem analysis and countermeasures on forestland protection and using in Lianshan County of Guangdong province (In Chinese). Central South For. Invent. Plan. 2009, 28, $16-22$.

62. Tang, C.N. Introduction to improve the structure of forestry in Guangdong (In Chinese). South China J. Econ. 1983, 3, 56-59.

63. Fan, F.; Wang, Y.; Qiu, M.; Wang, Z. Evaluating the temporal and spatial urban expansion patterns of Guangzhou from 1979 to 2003 by remote sensing and GIS methods. Int. J. Geogr. Inf. Sci. 2009, 23, 1371-1388.

64. Li, X. Integration of remote sensing and gis for monitoring and evaluating agricultural land loss - A case study of dongguan. Acta Geogr. Sin. 1997, 3, 279-287.

65. He, X.C.; Ding, Y.H.; He, J.H. Response characteristics of the East Asian winter monsoon to ENSO events. Chin. J. Atmos. Sci. 2008, 32, 335-344.

(C) 2013 by the authors; licensee MDPI, Basel, Switzerland. This article is an open access article distributed under the terms and conditions of the Creative Commons Attribution license (http://creativecommons.org/licenses/by/3.0/). 